\title{
New Effective Method Preservation of for Red Blood Cells by Means of Nanotechnology
}

\author{
Belousov A*, Malygon E, Yavorskiy V, and Belousova E \\ Laboratory of Applied Nanotechnology of Belousov, Kharkov Medical Academy of \\ Postgraduate Education, Ukraine
}

*Corresponding author: Andrey Belousov, Laboratory of Applied Nanotechnology of

Belousov Kharkov Medical Academy of Postgraduate Education, Ukraine Kharkov Regional Center of Blood Service, Ukraine, Tel: 38050-915-18-89; E-mail: an.belousov2012@ukr.net

\begin{abstract}
This study was devoted to the learning of the use of nanotechnology to correct the functional activity of red blood cells (RBCs) at the storage stages at a positive temperature. It was established that saline $\mathrm{NaCl}$, which had previously been processed by magnetite nanoparticles (ICNB) had a marked membrane-stabilizing effect, inhibits hemolysis and increasing the sedimentation stability of preserved RBCs. The complex analysis of the obtained data allowed to determine the primary mechanisms effect of the saline $\mathrm{NaCl}$, which had previously been processed by ICNB on the preserved RBCs. The proposed method of additive modernization of preserved RBCs was adapted to the production process. The optimisation results were obtained in creating a simple and practical method of additive modernization of preservation solutions that does not violate the compliance requirements, improves the quality, efficiency and safety transfusion of RBCs.
\end{abstract}

Keywords: Nanotechnology; Preserved Red Blood Cells; Magnetite Nanoparticles (ICNB); RBCs storage; production process

\section{Introduction}

Actuality Red blood cells (RBCs) transfusion is a critical, life-saving treatment for severe anemia caused by disease or chemotherapy, or by blood loss due to trauma or major surgery. For several decades RBCs components have been prepared as concentrates suspended in nutrient additive solution, which preserves and extends the shelflife of the RBCs component, allowing up to 6-7 weeks of refrigerated storage [1]. Nevertheless, during storage RBCs undergo a complex and progressive accumulation of physicochemical changes, collectively referred to as the RBCs storage lesion [2,3]. Recent clinical studies have identified RBCs transfusion as an independent risk factor for increased morbidities and mortalities in certain groups of patients, including trauma, cardiac surgery and the critically- ill (reviewed in [4-6]). Additionally, some of these studies have identified that older stored RBCs are 


\section{Nanomedicine \& Nanotechnology Open Access}

more strongly implicated in poorer outcomes compared to fresher RBCs [6]. In order to address these concerns, there is renewed interest to better understand the RBCs storage lesion and to find ways to ameliorate the deleterious effects of storage, thereby improving the quality, efficacy and safety of RBCs components for all transfusion recipients.

While increased research effort is being directed to better understand the effects of storage on RBCs and the potential impact on transfusion outcomes [7], slower progress is being made in finding ways to deter the detrimental effects of the RBCs storage lesion.

Over the past 15-20 years, research into the development of new additive solutions has focused on ways to maintain higher intracellular levels of ATP and 2.3-DPG during storage of RBC components [1].

Despite the RBCs having been a favourite experimental model for cellular biologists and biochemists, RBCs storage research has repeatedly demonstrated that a lot of fundamental biology about RBCs is still not well understood. The complexity of the inter-relationship between RBCs biochemistry, cytoskeletal structure and membrane properties have made it difficult to predict how RBCs will respond to different storage conditions. Exposure of RBCs to non-physiological storage environments has pointed to the existence of previously unknown biochemical mechanisms in RBCs, including apoptotic-like processes, ion and osmotic channels that behave differently than expected, exposure of new or altered receptors possibly due to oxidative and/or protease/glycosidase activities or altered senescence [811].

The benefits gained by improved RBCs component quality should more than justify any real or perceived inconvenience to the blood services in implementing adjustments to their processing procedures or additional processing costs of the introduction of new generation RBCs additive solutions. The bigger challenge that has hindered the advancement of this field is the significant financial burden and risk for manufacturers of blood collection systems to obtain licensure and to bring a new RBCs storage system to a market that is inherently based on very low profit margins, such as the blood services sector.

The financial burden to technology developers of new RBC storage systems is largely due to regulatory requirements, particularly those mandated by the FDA. In addition to in vitro data, the FDA requires in vivo data on the 24 hours post transfusion recovery of transfused autologous RBCs. Recently the FDA has tightened and increased the assessment and acceptance criteria making it potentially more difficult and expensive to bring new RBCs storage systems to market. Although the regulatory agencies are to be commended for focusing on the safety of new therapies and devices for patients, there are concerns that the regulatory requirements for RBC storage systems have become excessive and are hindering progress [12].

Another significant challenge for obtaining licensure of new RBCs storage systems is the inherent donor- related variability in stored RBCs quality. It has long been recognized that RBCs from some donors do not store well, as evidenced by higher levels of haemolysis at RBC component expiry 14 and poorer in vivo $24 \mathrm{hr}$ recovery data [13]. The relationship of specific donors and poorer quality of some stored RBCs components was confirmed in a recent paired cross-over study designed to compare manual and automated whole blood processing methods $[14,15]$. Technology developers are unwilling to take on the risk that a random poor quality RBCs component could jeopardise the success of licensure tests and clinical trials of their new blood storage systems and their significant financial investment.

In Ukraine, the first standardized and biocompatible magnetite nanoparticles for medical use were manufactured and patented in 1998. These are intracorporal nanobiocorrector of brand ICNB, magnetcontrolled sorbent of brand MCS-B, and biologically active nanodevice of brand Micromage-B [16].

It is well established that the magnetite nanoparticles effectively modulate the metabolic processes in leukocytes, regulate activity of the enzyme link of the antioxidant system in erythrocytes in healthy and sick patients [17-19]. Previously the complex investigations that were performed in the study of the influence on metabolism of cells by preparations of nanotechnology show that in whole standardized biocompatibility of magnetite nanoparticles have nonspecific and modulated effect on metabolic processes. Research of ultra structure investigations of the reticuloendothelial system (liver, lungs and kidneys) it was proved that after injection of biocompatibility magnetite nanoparticles into a vein caused nonspecific activation of the metabolic processes, increase adaptive mechanisms and potential of organelle cells, acceleration of reparative processes a level of membranes and macromolecules [18,20,21]. Existing sorption and indirect (magnetic) effects not only allow 


\section{Nanomedicine \& Nanotechnology Open Access}

selectively absorb the protein of surface membrane cells by magnetite nanoparticles (according to the principle of magnetophoreses), but also to prevent the oxidative modification of proteins by way of stabilizing the active groups, normalizing a state of receptors that are located on the surface membrane of cells, increasing activity of enzymes' membrane-bound [22-24].

Recent scientific work related to use of magnetite nanoparticles (ICNB) in contrast means in an MRI investigation of cancer reliably was shown that nanoparticles cause reversible changes associated with a temporary increase in the mobility of hydrogen protons in the pericellular fluid that inevitably modifies the metabolism in malignant cells [25]. The results of these investigations have not only widened the understanding of the mechanisms of action of nanoparticles on condition outside and intracellular spaces but also have revealed new aspects of the cellular(cells) metabolism, determined the membrane role of cellular enzymes in the regulation processes of metabolism [23,25-28].

Also, it was established that extra corporally processing the blood by nanoparticles of MCS-B reliably reduces activity of $\mathrm{Ca}, \mathrm{Mg}$ - ATPHese of erythrocytes. Currently, studies have shown that magnetite nanoparticles are able to inhibit hemolysis of heparinized blood, increase the activity of ATP and 2.3 DPH in red blood cells, regulate transmembrane metabolism and inhibit eryptosis $[23,29,30]$.
The above was the basis for the choice of the theme of this study, devoted to the learning of the use of nanotechnology to correct the functional activity of red blood cells at the storage stages at a positive temperature.

The main purpose of the first stage of the study is to develop a simple and practical method of additive modernization of preservation solutions that does not violate the compliance requirements, improves the quality, efficiency and safety transfusion of red blood cells.

\section{Materials and methods}

Materials: 1. Standardized intra corporeal nano bio corrector of ICNB was taken as nanoparticles. Magnetite nanoparticles synthesized by co-precipitation method. The main physics and chemical properties of ICNB the following data and also in Tables 1-4; Figures 1,2 were presented:

- Concentration of the colloidal solution of magnetite nanoparticles in physiology solution of $\mathrm{NaCl}$ is $0.0225 \%$.

- Theoretical osmolality of colloid solution is 500 mosmol/l

- Size of magnetite nanoparticles is $6-12 \mathrm{~nm}$;

- Total area of surface magnetite of nanoparticles Ss = $800-1200 \mathrm{~m}^{2} / \mathrm{g}$

- Magnetization of saturation Is $=2.15 \mathrm{\kappa A} / \mathrm{m}$;

- $\zeta$ - Potential $=-19 \mathrm{mV}$.

\begin{tabular}{|c|c|c|c|c|c|c|}
\hline Phase name & a (Á) & b $(\AA \hat{)})$ & c $(\hat{A})$ & alpha (град) & beta (град) & gamma (град) \\
\hline magnetite low & 8.39 & 8.39 & 8.39 & 90 & 90 & 90 \\
\hline magnetite low, syn & 5.93 & 5.93 & 14.7 & 90 & 90 & 120 \\
\hline Johannsenite & 9.89 & 9.06 & 5.28 & 90 & 105.5 & 90 \\
\hline
\end{tabular}

Table 1: The calculated lattice parameters of the phases

\begin{tabular}{|c|c|c|c|c|c|c|c|c|}
\hline Compound & Wt\% & StdErr & El & Weight\%/ $\mathbf{O}_{\mathbf{2}}$ & StdErr & El & Weight\% & StdErr \\
\hline $\mathrm{Fe}_{3} \mathrm{O}_{4}$ & 97.37 & 0.09 & $\mathrm{Fe}$ & 68.4 & 0.07 & $\mathrm{Fe}$ & 97.62 & 0.09 \\
\hline $\mathrm{CaO}$ & 2.26 & 0.07 & $\mathrm{Ca}$ & 1.71 & 0.05 & $\mathrm{Ca}$ & 2.3 & 0.07 \\
\hline $\mathrm{P}_{2} \mathrm{O}_{5}$ & 0.28 & 0.027 & $\mathrm{Px}$ & 0.122 & 0.012 & $\mathrm{Px}$ & 0.157 & 0.015 \\
\hline $\mathrm{MnO}$ & 0.255 & 0.013 & $\mathrm{Mn}$ & 0.198 & 0.01 & $\mathrm{Mn}$ & 0.278 & 0.014 \\
\hline $\mathrm{SiO}_{2}$ & 0.098 & 0.027 & $\mathrm{Si}$ & 0.046 & 0.013 & $\mathrm{Si}$ & 0.059 & 0.016 \\
\hline $\mathrm{SO}_{3}$ & 0.032 & 0.013 & $\mathrm{Sx}$ & 0.0126 & 0.0051 & $\mathrm{Sx}$ & 0.0164 & 0.0066 \\
\hline $\mathrm{Cl}$ & 0.028 & 0.009 & $\mathrm{Cl}$ & 0.028 & 0.009 & $\mathrm{Cl}$ & 0.038 & 0.012 \\
\hline
\end{tabular}

Table 2: Determination of percent composition of the ICNB by X-ray spectrometer ARL OPTIM'X (semi- quantitative analysis) 


\section{Nanomedicine \& Nanotechnology Open Access}

\begin{tabular}{|c|c|c|c|}
\hline Phase & Formula & Space group & № Card Database ICDD \\
\hline magnetite low & $\mathrm{Fe}_{2} .886 \mathrm{O}_{4}$ & $227: \mathrm{Fd}-3 \mathrm{~m}$, choice-2 & 10861339 (ICDD) \\
\hline magnetite low, syn & $\mathrm{Fe}_{3} \mathrm{O}_{4}$ & $166: \mathrm{R}-3 \mathrm{~m}$, hexagonal & 10716766 (ICDD) \\
\hline Johannsenite & $\mathrm{Ca} \mathrm{Mn}+2 \mathrm{Si}_{2} \mathrm{O}_{6}$ & $15: \mathrm{C} 12 / \mathrm{C} 1$, unique-b,cell-1 & 380413 (ICDD) \\
\hline
\end{tabular}

Table 3: X-ray analysis of ICNB in X-ray diffractometer Rigaku Ultima IV (CuK $\alpha, \mathrm{K} \beta$ filter - Ni), one- coordinate DTeX semiconductor detector

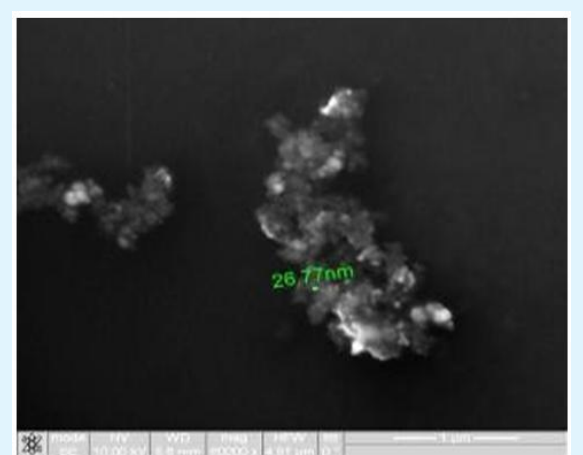

Figure 1: Study of magnetite nanoparticles with use microscope ion-electronic raster-type Quanta 2003 D

\begin{tabular}{|c|c|}
\hline \multicolumn{2}{|c|}{$\begin{array}{l}\text { Figure 2: Study of magnetite nanoparticles with use } \\
\text { microscope electronic translucent JEM- } 2100\end{array}$} \\
\hline $\begin{array}{l}\text { Phases (method of corundum } \\
\text { numbers) }\end{array}$ & Content, \% \\
\hline magnetite low & 71 \\
\hline magnetite low, syn (hexagonal) & 29 \\
\hline
\end{tabular}

Table 4: The phases of magnetite of nanoparticles (RIR method; error $8 \pm 3 \%$ )

1. $0.9 \% \mathrm{NaCl}$ solution.

2. $0.9 \% \mathrm{NaCl}$ solution which previously was processed by ICNB in ratio 4:1.

\section{Object of Research}

- red blood cells (RBCs) into bags containing anticoagulant citrate, nutrient phosphate and dextrose (CPD);

- Red blood cells (RBCs) into bags containing anticoagulant citrate, nutrient phosphate, dextrose and adenine (CPDA-1).

\section{Methods}

Before starting the experience with red blood cells (RBCs) we used visual assessment by comparison of the brightness of the imagines different variants of solutions. These were: ICNB, $0.9 \% \mathrm{NaCl}$ solution and $0.9 \% \mathrm{NaCl}$ solution that had been treated by magnetite nanoparticles (ICNB).

The tests were performed on the Siemens MRtomagraphy Magneton Concerto with power magneticfield $0.2 \mathrm{~T}$.

The axial tomograms were received:

1. T1 - the self-weighted sequences of Echo Spin of TR 50 $\mathrm{ms}$, TE $17 \mathrm{~ms}$ the field of review the $250 \mathrm{~mm}$, the thickness cut $2 \mathrm{~mm}$.

2. T2 - the self-weighted sequences Echo Gradient of TR 500 $\mathrm{ms}$, TE $17 \mathrm{~ms}$ the field of review a $180 \mathrm{~mm}$, the thickness cut $4 \mathrm{~mm}$.

Of each bag of $3 \mathrm{ml}$ amounts of red blood cells was distributed into 20 sterile glass tubes. Then, into the first 10 tubes of control were added of $2 \mathrm{ml}$ amounts $0.9 \% \mathrm{NaCl}$ solution. Into the next 10 tubes of test were added of $2 \mathrm{ml}$ amounts $0.9 \% \mathrm{NaCl}$ solution, which previously was processed by ICNB.

Thus, the distribution of tubes was as the follows:

Tubes of control:

- $3 \mathrm{ml}$ of red blood cells (CPD) $+2 \mathrm{ml} 0.9 \% \mathrm{NaCl}$ solution $(n=10)$;

- $3 \mathrm{ml}$ of red blood cells (CPDA-1) $+2 \mathrm{ml} 0.9 \% \mathrm{NaCl}$ solution $(\mathrm{n}=10)$.

Tubes of test:

- $3 \mathrm{ml}$ of red blood cells (CPD) $+2 \mathrm{ml} 0.9 \% \mathrm{NaCl}$ solution that previously was processed by ICNB in ratio $4: 1$ $(\mathrm{n}=10)$; 


\section{Nanomedicine \& Nanotechnology Open Access}

- $3 \mathrm{ml}$ of red blood cells (CPDA-1) +2 $\mathrm{ml} 0.9 \% \mathrm{NaCl}$ solution that previously was processed by ICNB in ratio $4: 1(n=10)$.

The state of red blood cells was determined visually by the registration of signs of hemolysis. Also, hemolysis was controlled by photometric method by means Plasma / Low $\mathrm{Hb}$ and GPHP-01 devices. The centrifuge mark of SM70M-07 was used to obtain supernatant. Hematocrit (HCT) was calculated by means hematocrit ruler and using the formula:

$$
\mathrm{HCT}=\frac{\text { Free } \mathrm{Hb} \times(1-\mathrm{HCT})}{\text { Common } \mathrm{Hb}} \times 100 \%
$$

Morphology of the red blood cells was studied by direct microscopic method. Sedimentation stability of red blood cells was studied by Panchenkov's method. Change in the acidity of the red blood cells was performed by means of $\mathrm{pH}$ metric.

Tests were carried out in six stages: day 1 - I, day 7 - II, day 14 - III, day 21 - IV, day 28 - V, day 35 - VI. The blood after performance of the biochemical investigation was stored in the refrigerating chamber at temperature $+4^{\circ} \mathrm{C}$.

Statistically processing the obtained results was carried out by parametrical method of variation statistics by Student criterion. Processing the obtained data was carried out by means of Excel.

\section{Results and Discussion}

Results of visual assessment of the images brightness used in experiment liquids at the MRI are represented in Figure 3.

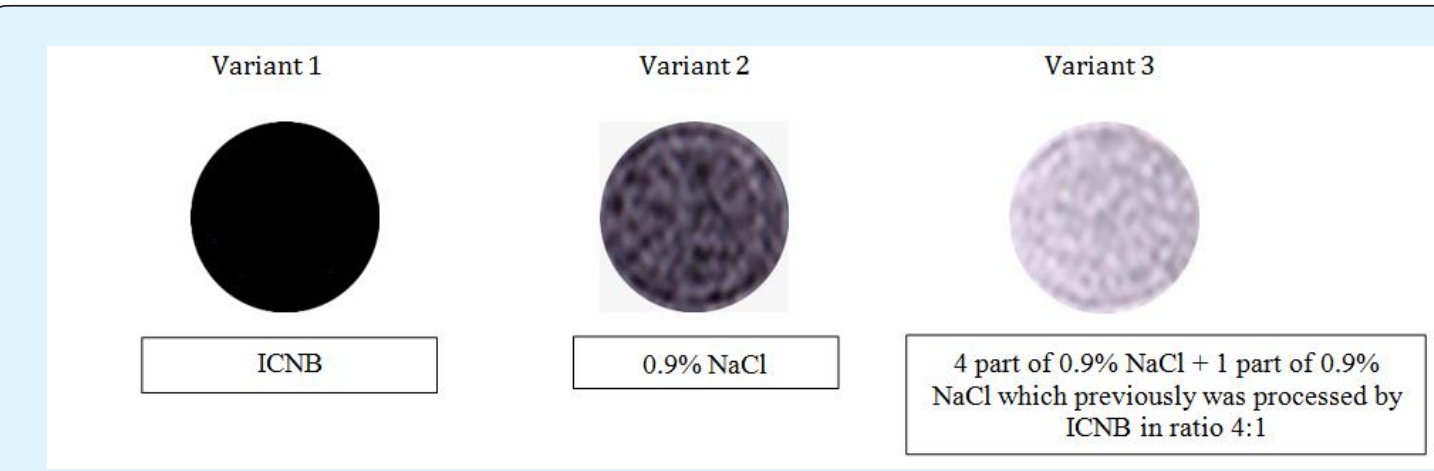

Figure 3: Images of fluids that were studied in the research at the MRI.

Figure 3 illustrates the difference of image brightness in liquids compared at the MRI. The order of the brightness increase is the following: ICNB, $0.9 \% \mathrm{NaCl}$ solution, $0.9 \% \mathrm{NaCl}$ solution that was treated by nanoparticles of ICNB. The difference in brightness of images is explained in the following way:

- Variant 1: Magnetite nanoparticles of ICNB reduce the mobility of hydrogen protons in the liquid medium $(0.9 \% \mathrm{NaCl}$ solution). Therefore, the image brightness was very low in the MRI.

- Variant 2: Rising mobility of hydrogen protons in the intact $0.9 \% \mathrm{NaCl}$ solution increased brightness in comparison with Variant 1.

- Variant 3: Mobility of hydrogen protons in $0.9 \% \mathrm{NaCl}$ solution that has previously been processed ICNB nanoparticles is maximized. Therefore, the image brightness is much higher than before (in the previous variants).
Thus, previously conducted research clearly shows that the nanoparticles of ICNB change the mobility and the orientation of the hydrogen atoms in liquids that are registered in the visual evaluation of MRI.

The next set of studies was essential and aimed at studying of functional activity of red blood cells at the storage stages at a positive temperature after by modifying the mobility and spatial orientation of hydrogen protons in the pericellular fluid using magnetite nanopatricles of ICNB.

A study of the sedimentation stability of RBCs showed a highly significant difference between control and test data. Data of sedimentation stability of the RBCs at the stages of a study were presented in Figure 4. 


\section{Nanomedicine \& Nanotechnology Open Access}

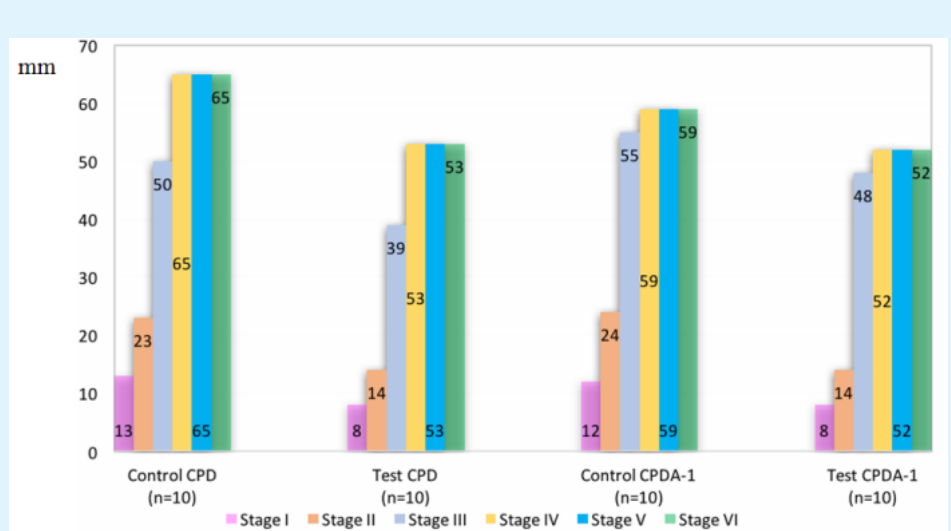

Figure 4: Study of the sedimentation stability of RBCs at the stages $(M \pm m ; p<0.001 ; n=10)$.

Figure 4 shows that sedimentation stability of RBC in test tubes are reliably more highly $(\mathrm{p}<0.001)$ then in control tubes at stages of research. It should be said that negative surface charge of human RBCs's results primarily from the presence of ionogenic carboxyl groups of sialic acids on the cell surface [31-33]. The value of the charge is determined by the amount of adenosine three phosphates (ATP). ATP is macroergic compounds, the product of glycolysis. The sedimentation stability of RBC is determined by the amount of ATP.

In this case, the change of mobility and spatial orientation of the hydrogen protons in the extracellular liquid significantly increased the sedimentation stability of RBCs in the test compared to the control. For greater clarity results of RBCs sedimentation is shown in Figure 5.

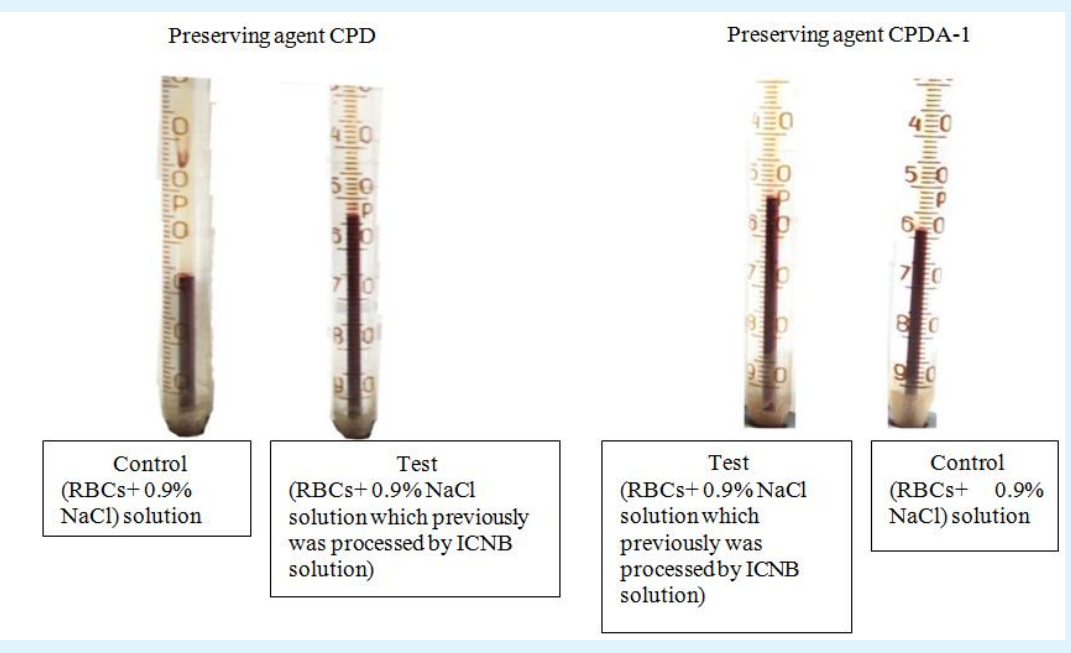

Figure 5: Sedimentation stability of erythrocytes at the stage VI of the study.

Figure 5 is showing that with preserved in the anticoagulant CPD the sedimentation stability in the control was $62 \mathrm{~mm}$; in the test - $53 \mathrm{~mm}$. With preserved in the anticoagulant CPDA-1: control - $58 \mathrm{~mm}$; test - 52 $\mathrm{mm}$.

Thus, following the logic of the above reasoning, if improving sedimentation stability of RBC is associate with an increase in ATP, then the isotonic solution which previously was processed by ICNB should actively stabilize the membranes of RBCs and inhibit hemolysis. Therefore, the next investigation was to study the hemolysis processes preserved of the RBCs at various stages. Results of the visual assessment hemolysis of erythrocytes in various aspects of exposure are presenting in Figure 6. 


\section{Nanomedicine \& Nanotechnology Open Access}
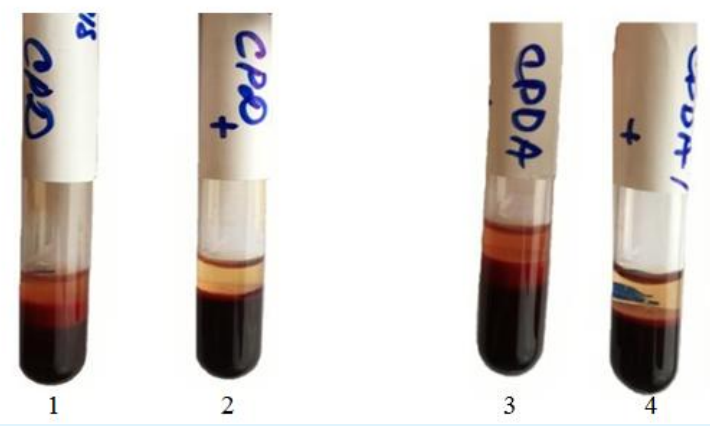

Figure 6: Visual assessment hemolysis of erythrocytes in various aspects of exposure at the stage VI.
Notes: 1 - RBC (preserving agent CPD) $+0.9 \% \mathrm{NaCl}$ solution; 2 - RBCs (preserving agent CPD) $+0.9 \% \mathrm{NaCl}$ solution which previously was processed by ICNB; 3 - RBCs (preserving agent CPDA-1) $+0.9 \% \mathrm{NaCl}$ solution; 4 - RBCs (preserving agent CPDA- 1 ) $+0.9 \% \mathrm{NaCl}$ solution which previously was processed by ICNB.

Figure 7 shows that in the control tubes at the stage VI of the study there are pronounced signs of hemolysis. In contrast, hemolysis is not recorded in test tubes. Visual analysis was supplemented by objective data of the photometric method, as well as the method of calculation of hematocrit.

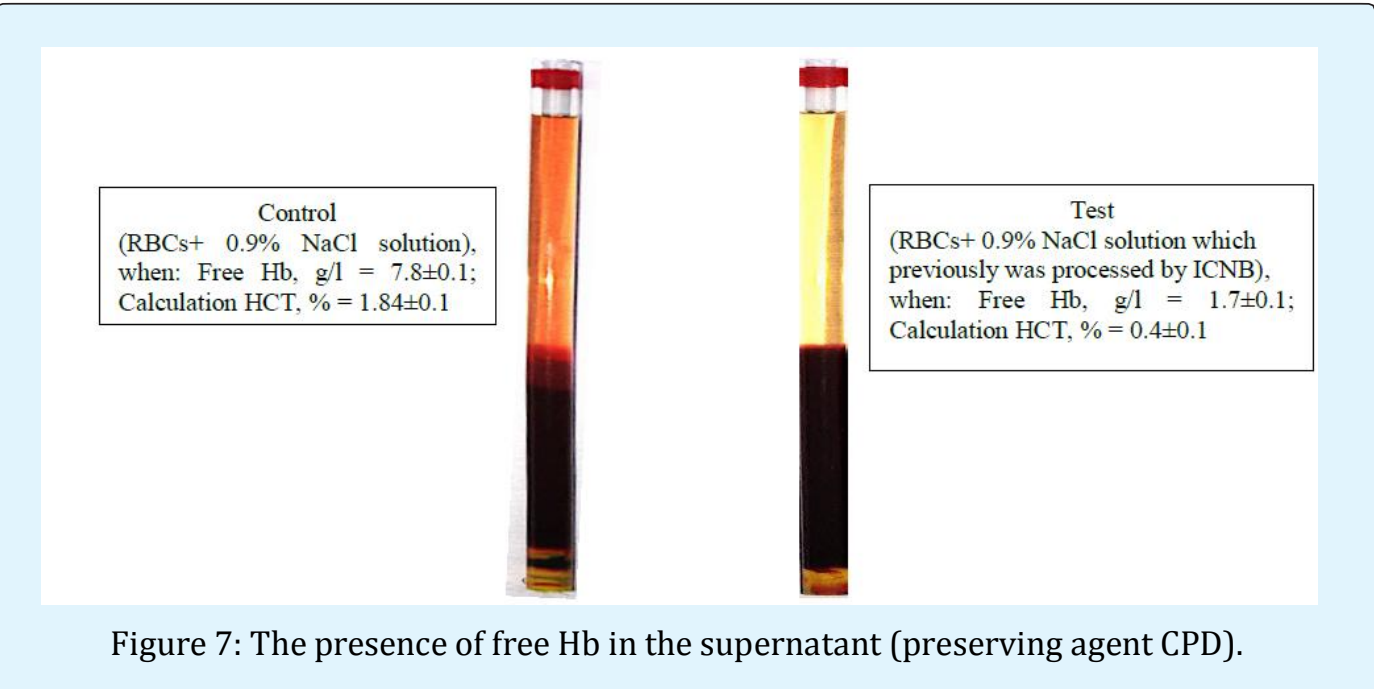

Objective data of free $\mathrm{Hb}$ and calculated HCT at the stage

VI of the study are presented in Table 5.

\begin{tabular}{|c|c|c|c|c|}
\hline \multirow{2}{*}{ Preservatives } & \multirow{2}{*}{ Variants } & \multicolumn{2}{|c|}{ Stage VI } & \multirow[b]{2}{*}{$\mathbf{p}$} \\
\hline & & Free Hb, g/l & Calculation HCT, \% & \\
\hline \multirow{2}{*}{ CPD } & Control $(n=10)$ & $7.8 \pm 0.1$ & $1.84 \pm 0.1$ & $<0.001$ \\
\hline & Test $(n=10)$ & $1.7 \pm 0.1$ & $0.4 \pm 0.1$ & $<0.001$ \\
\hline \multirow{2}{*}{ CPDA-1 } & Control $(n=10)$ & $8.0 \pm 0.1$ & $1.9 \pm 0.1$ & $<0.001$ \\
\hline & Test $(\mathrm{n}=10)$ & $1.6 \pm 0.1$ & $0.5 \pm 0.1$ & $<0.001$ \\
\hline
\end{tabular}

Table 5: The indicators of free $\mathrm{Hb}$ and calculated HCT at the stage VI of the study at baseline values: $\mathrm{Hb}=154 \mathrm{~g} / \mathrm{l} ; \mathrm{CT}=$ 0.46 .

The data in Table 5 indicate that in test tubes the average content of free $\mathrm{Hb}$ in the VI stage of the study $6.25 \pm 0.1 \mathrm{~g} / \mathrm{l}$ were less than controls; and the average calculation HCT was lower by $1.42 \%$.

Thus, the objective indicators of Table 5 are highly reliable $(\mathrm{p}<0.001)$ and confirm the obtained visual effect of inhibiting hemolysis of preserved RBCs by physiological solution, which was pretreated by ICNB. Microscopic observation of changes in the morphology of RBCs was a logical continuation of the study of the erythrocyte membranes stabilization effect. The results of microscopic examination of the morphology of 


\section{Nanomedicine \& Nanotechnology Open Access}

erythrocytes in different variants of preservation and treatment are shown in Figure 8.

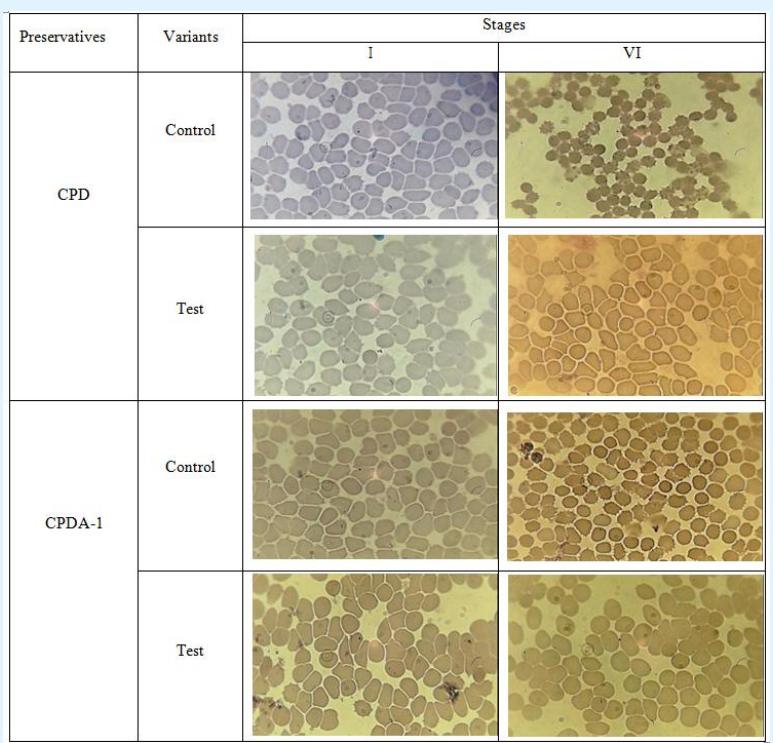

Figure 8: The microscopic examination of the morphology of erythrocytes in different variants of preservation and treatment.

Figure 8 clearly demonstrates that microscopically in the control variant at the VI stage of the study, widespread appearance of spheroechinocytes is observed.
On the contrary, in the test variants, the shape of red blood cells at the stage VI was unchanged. Pathological changes in the RBC's shape and size in the control variants are most likely associated with inhibition of glycolysis processes [34]. Consequently, the number of ATP and 2.3 DPG decreases, the permeability of the erythrocyte membranes is disturbed, the state of the hemoglobin buffer changes. As a result, the $\mathrm{pH}$ of intracellular and extracellular media is changes.

The decrease in the formation of 2.3 DPG leads to the acidulation of intracellular environment of the RBCs. Deoxygenated hemoglobin which was previously formed actively binds the $[\mathrm{H}+]$ that comes from the extracellular environment and alkalizes the extracellular environment. The effect of RBC reduction, the appearance of widespread spheroechinocytes is observed in microscopy. Subsequently, oxy hemoglobin moves to the extracellular environment as a result of processes intensification destruction of the membranes of RBCs. The accumulation of oxygenated hemoglobin in the extracellular environment causes by shifting towards the acid of the $\mathrm{pH}$.

The above mechanisms have been confirmed in the study of the dynamics of $\mathrm{pH}$ changes in the extracellular medium of preserved of the RBCs. The dynamics of $\mathrm{pH}$ changes in the extracellular medium of RBCs storage at key stages of the study on the example of preserving agent CPD is shown in Figure 9.

\begin{tabular}{|c|c|c|c|c|}
\hline & Preservatives & \multicolumn{3}{|c|}{ Stages } \\
\hline & CPD & I & $\mathrm{V}$ & VI \\
\hline \multicolumn{5}{|l|}{ Control } \\
\hline & $\mathrm{pH}=5-6$ & $\mathrm{pH}=7.3-7.4$ & $\mathrm{pH}=7.2-7.3$ & $\mathrm{pH}=7.1-7.2$ \\
\hline \multicolumn{5}{|l|}{ Test } \\
\hline & $\mathrm{pH}=5-6$ & $\mathrm{pH}=7.3-7.4$ & $\mathrm{pH}=7.3-7.4$ & $\mathrm{pH}=7.4-7.5$ \\
\hline
\end{tabular}

Figure 9: Dynamics of $\mathrm{pH}$ changes in the extracellular medium of RBCs storage at key stages of the study on the example of preserving agent CPD.

Figure 9 demonstrates that despite the initial acidic environment of the preservative $(\mathrm{pH} \mathrm{CPD}=5-6)$ in the control and test in the extracellular medium at the first stage of the study alkaline $\mathrm{pH}$ is registered. The appearance of differences in the dynamics of change in the color of the $\mathrm{pH}$ indicator between the control and the test is clearly observed in the subsequent stages of the study. So, against the background of the appearance of hemolysis signs significant decrease of the $\mathrm{pH}$ to 7.1-7.2 in the control at the VI stage of the study is registered. On 


\section{Nanomedicine \& Nanotechnology Open Access}

the contrary, the $\mathrm{pH}$ of the extracellular medium remains relatively stable and corresponds to the parameters 7.47.5 in the test at the VI stage of the study.

Thus, obtained result, show that change in cytoplasmic $\mathrm{pH}$ is both necessary and sufficient for the shape changes of human erythrocytes [35]. The effect of hemolysis inhibition by the method of additive modernization of preservation solutions that adapted to the manufacture process at the VI stage of the study is shown in Figure 10.

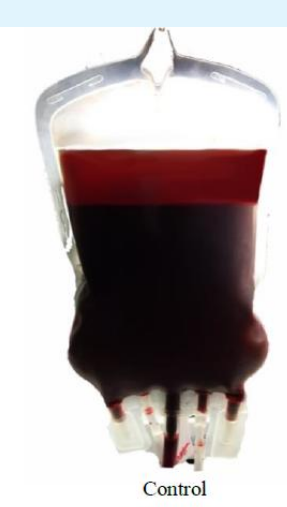

(Free $\mathrm{Hb}, \mathrm{g} / \mathrm{l}=7.8 \pm 0.1$ Calculation HCT, $\%=1.84 \pm 0.1)$

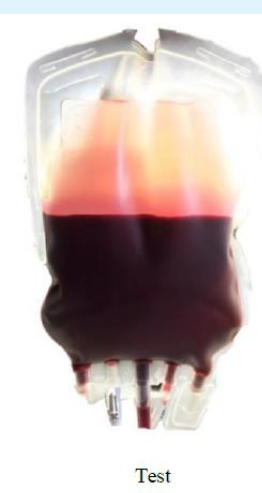

(Free $\mathrm{Hb}, \mathrm{g} / \mathrm{l}=1.7 \pm 0.1$; Calculation HCT, $\%=0.4 \pm 0.1$ )
Figure 10: The hemolysis inhibition effect with using method of additive modernization of preservative solutions adapted to the manufacture process at stage VI of the study.

\section{Conclusion}

As a result of the studies it was found that physiologic solution $\mathrm{NaCl}$ which previously was processed by ICNB and added to the preserved of the red blood cells actively inhibits of hemolysis processes of RBCs at the storage stages at a positive temperature. A comprehensive analysis of data revealed the primary mechanisms of the effect modernized of the saline solution on the preserved RBCs. It was established that saline $\mathrm{NaCl}$, which had previously been processed by magnetite nanoparticles (ICNB) had a marked membrane-stabilizing effect, inhibits hemolysis and increasing the sedimentation stability of preserved RBCs. In General, these effects provide the sustainability of the functional activity of preserved RBCs in during storage.

Thus, the first optimistic results were obtained on the way of creation a simple and practical method of additive modernization of preservation solutions that does not violate the compliance requirements, improves the quality, efficiency and safety transfusion of red blood cells.

\section{References}

1. Hess JR (2006) An update on solutions for red cell storage. Vox Sang 91(1): 13-19.

2. Högman CF, Meryman HT (1999) Storage parameters affecting red blood cell survival and function after transfusion. Transfus Med Rev 13(4): 275-296.

3. Hess JR (2010) Red cell changes during storage. Transfus Apher Sci 43(1): 51-59.

4. Zimrin AB, Hess JR (2009) Current issues relating to the transfusion of stored red blood cells. Vox Sang 96(2): 93-103.

5. van de Watering L (2011) Red cell storage and prognosis. Vox Sang 100(1): 36-45.

6. Wang D, Sun J, Solomon SB, Klein HG, Natans on C (2012) Transfusion of older stored blood and risk of death: a meta-analysis. Transfusion 52(6): 1184-1195.

7. Glynn SA (2010) The red cell storage lesion: a method to the madness. Transfusion 50(6): 1164-1169.

8. D'Amici GM, Rinalducci S, Zolla L (2007) Proteomic analysis of $\mathrm{RBC}$ membrane protein degradation during blood storage. J Proteome Res 6(8): 32423255 .

9. Verhoeven A, Hilarius P, Dekkers D, Lagerberg JW, de Korte D (2006) Prolonged storage of red blood cells affects aminophospholipid translocase activity. Vox Sang 91(3): 244-251.

10. Sparrow RL, Veale MF, Healey G, Payne KA (2007) Red blood cell (RBC) age at collection and storage influence RBC membrane-associated carbohydrates and lectin binding. Transfusion 47(6): 966-968.

11. Bosman GJ, Lasonder E, Groenen-Döpp YA, Willekens FL, Werre JM, et al. (2010) Comparative proteomics of erythrocyte aging in vivo and in vitro. J Proteomics 73(3): 396-402.

12. Hess JR (2012) Scientific problems in the regulation of red blood cell products. Transfusion 52(8): 18271835. 


\section{Nanomedicine \& Nanotechnology Open Access}

13. Hess JR, Sparrow RL, van der Meer PF, Acker JP, Cardigan RA, et al. (2009) Red blood cell hemolysis during blood bank storage: using national quality management data to answer basic scientific questions. Transfusion 49(12): 2599-2603.

14. Dumont LJ, AuBuchon JP (2008) Evaluation of proposed FDA criteria for the evaluation of radiolabeled red cell recovery trials. Transfusion 48(6): 1053-1060.

15. McAteer MJ, Dumont LJ, Cancelas J, Rugg N, Vassallo R, et al. (2010) Multi-institutional randomised control study of haemolysis in stored red cell units prepared manually or by an automated system. Vox Sang 99(1): 34-43.

16. Belousov AN (2011) The use of magnetite nanoparticles in applied medicine. International Journal of Nano Dimension 2(1): 25-28.

17. Belousov AN, Belousova E Yu (2002) The first steps in discovery new mechanisms of cellular regulation in means by nanotechnology preparations. $\mathrm{X}$ International Conference New Information Technologies in Medicine and Ecology. - Yalta, Gursuf, Pp: 420-425.

18. Belousov AN, Belousova E Yu (2012) Mechanisms cell regulation by nanotechnology preparations (MCS-B). BioNanotech Conference \& Expo, Santa Clura, CA, USA.

19. Belousov AN (2000) Effect of magnet controlled sorbent on parameters of acid-base balance of the blood and the processes of glycolysis in erythrocytes. Pain, anesthesia and intensive care: 263-265.

20. Belousov AN, Nevzorov VP (1997) Ultrastructure of cells in the kidneys and lungs of rabbits after administration of magnetite // International collection of scientific papers IV Scientific and Practical Conference on the Creation and Testing of New Drugs, Moscow, Pp: 77-87.

21. Belousov AN, Nevzorov VP (1997) Ultrastructure of liver cells after administration of magnetite // International collection of scientific papers IV Scientific and Practical Conference on the Creation and Testing of New Drugs, Moscow Pp: 71-77.

22. Belousov AN (2009) Spectrum of Application Magnetite Nanopaticles in Medicine. Nanotech 2(3): 154-157.
23. Belousov AN (2012) Effect on hemolysis and transport ATPase activity of erythrocytes by means nanopareticles of magnetit controlled sorbent (MCSB). Pain, anesthesia and intensive care. Kiev: 26-28.

24. Belousov AN (2017) Ultrastructure of Hepatic Cells after Intravenous Injection of Magnetite Nanoparticles ICNB. J Cell Mol Biol 2(1): 1-4.

25. Belousov AN (2013) Application Magnetite of Nanoparticles (ICNB Preparation) as MagneticallyResonant Contrasting Means During Visualization of Tumours. Clean Technology and Sustainable Industries Organization: 379-381.

26. Belousov AN (2012) Investigation of the influence nanoparticles of magnetite controlled sorbent (MCSB) on the functional activity of erythrocytes. Prospects Medicine and Biology: 94-97.

27. Belousov AN (2014) Myth and Reality Application of Magnetite Nanoparticles as Selective Contrasting Means of the Malignant Tumors in MRI Investigation. Journal Biomedical Engineering Research 2(3): 147152.

28. Belousov AN (2014) Application of Biocompatible Standardized Magnetite Nanoparticles (ICNB) In MRI Investigation of Malignant Tumour. Journal Nanomaterials \& Molecular Nanotechnology: 17-21.

29. Belousov AN (2014) Nanotechnology and Discovery of a New Factor Which Influences on Permeability of Erythrocytes and Eryptosis. Journal of Materials Science and Engineering A 4(11): 367-372.

30. Belousov AN (2017) Reducing of Erythrocytes Destruction by Means of Medicine Nanotechnology (Magnet- Controlled Sorbent brand of MCS-B). J Cell Mol Biol 2: 005.

31. Eylar EH, Madoff MA, Brody OV, Oncley JL (1962) The contribution of sialic acid to the surface charge of the erythrocyte. J Biol Chem 237(6): 1993-2000.

32. Cook GMW, Heard DH, Seaman GVF (1961) Sialic acids and the electrokinetic change of the human erythrocyte. Nature 191(4783): 44-47.

33. Jan KM, Chien S (1973) Role of Surface Electric Charge in Red Blood Cell Interactions. J Gen Physiol 61(5): 638-654. 


\section{Nanomedicine \& Nanotechnology Open Access}

34. Sakota D, Sakamoto R, Yokoyama N, Kobayashi M, Takatani S (2009) Glucose depletion enhances sensitivity to shear stress-induced mechanical damage in red blood cells by rotary blood pumps. Artificial Organs 33(9): 733-739.
35. Gedde MM, Davis DK, Huestis WH (1997) Cytoplasmic $\mathrm{pH}$ and human erythrocyte shape. Biophys J 72(3): 1234-1246.

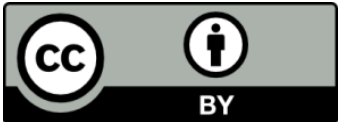

